\title{
TITLE:
}

\section{Palladium-Catalyzed Amination of Aryl Sulfides with Aliphatic Amines}

$\operatorname{AUTHOR}(\mathrm{S}):$

Gao, Ke; Yorimitsu, Hideki; Osuka, Atsuhiro

\section{CITATION:}

Gao, Ke ...[et al]. Palladium-Catalyzed Amination of Aryl Sulfides with Aliphatic Amines. European Journal of Organic Chemistry 2015, 2015(12): 2678-2682

\section{ISSUE DATE:}

2015-03-06

URL:

http://hdl.handle.net/2433/198449

\section{RIGHT:}

This is the peer reviewed version of the following article: Gao, K., Yorimitsu, H. and Osuka, A. (2015), Palladium-Catalyzed Amination of Aryl Sulfides with Aliphatic Amines. Eur. J. Org. Chem. 2015: 2678-2682, which has been published in final form at http://dx.doi.org/10.1002/ejoc.201500226.; 許諾条件により本文ファイルは2016-03-06に公開.; This is not the published version. Please cite only the published version.; この論文は出版社版でありません。引用の際には出版社版

をご確認ご利用ください。 


\title{
Palladium-Catalyzed Amination of Aryl Sulfides with Aliphatic
}

\section{Amines}

\author{
Ke Gao, ${ }^{[a]}$ Hideki Yorimitsu, ${ }^{*[a, b]}$ and Atsuhiro Osuka ${ }^{[a]}$
}

\begin{abstract}
Conditions for palladium-NHC-catalyzed amination of aryl sulfides have been improved to allow for the use of aliphatic amines as well as aromatic amines and to exhibit wider functional group tolerance. The KHMDS-mediated amination of heteroaryl sulfides could proceed without palladium. Based on distinct difference in reactivities of $\mathrm{C}-\mathrm{Br}$ and $\mathrm{C}-\mathrm{S}$ bonds, sequential amination of bromothioanisole proceeds to install two different alkylamino groups onto the aromatic ring in one pot.
\end{abstract}

\section{Introduction}

The prevalence of aniline derivatives in pharmaceutical, agrochemical, and material sciences has been inspiring organic chemists to develop efficient methods for carbon-nitrogen bond formation. ${ }^{[1]}$ After Buchwald's and Hartwig's breakthrough on palladium-catalyzed amination of aryl halides with anilines, a number of catalytic amination reactions of aryl halides/pseudohalides have been reported. ${ }^{[2,3]}$ Recently, a series of stable and low cost phenol derivatives ${ }^{[4]}$ such as carbamates, ${ }^{[5]}$ sulfamates, ${ }^{[5,6]}$ pivalate esters, ${ }^{[7]}$ phosphates ${ }^{[8]}$ and even challenging methyl ethers ${ }^{[9]}$ have been introduced as substrates of amination reactions. This situation encouraged us to discover new coupling partners for amination reactions other than oxygen-based molecules.

Although a carbon-sulfur bond has reactivity comparable to carbon-halogen bonds, it has been used much less frequently in transition metal-catalyzed cross-coupling reactions due to the strong affinity of sulfur atom to transition metals. ${ }^{[10]}$ Therefore, development of new catalytic transformations of $\mathrm{C}-\mathrm{S}$ bonds would be an important challenge since $\mathrm{C}-\mathrm{S}$ bonds exist widely in organic feedstock, synthetic intermediates, and useful products. As a part of our recent contribution to catalytic C-S bond cleavage ${ }^{[11]}$ we reported the first palladium-catalyzed amination of aryl sulfides (Scheme 1). ${ }^{[11 \mathrm{c}]}$ A palladium-NHC ( $\mathrm{N}$-heterocyclic carbene) precatalyst SingaCycle-A3 exhibited excellent reactivity on $\mathrm{C}-\mathrm{S}$ bond cleavage. However, there still remain some drawbacks: (1) the amine nucleophile is limited to aniline derivatives and (2) carbonyl functionalities are incompatible with highly basic conditions (excess $\mathrm{KN}\left(\mathrm{SiMe}_{3}\right)_{2}, 100{ }^{\circ} \mathrm{C}$ ). Here, we report a milder and more general protocol for catalytic amination of aryl sulfides.

[a] Dr. K. Gao, Prof. Dr. H. Yorimitsu, Prof. Dr. A. Osuka Department of Chemistry, Graduate School of Science Kyoto University

Sakyo-ku, Kyoto 606-8502 (Japan)

E-mail: yori@kuchem.kyoto-u.ac.jp

[b] Prof. Dr. H. Yorimitsu

ACT-C, JST

Sakyo-ku, Kyoto 606-8502 (Japan)

Supporting information for this article is given via a link at the end of the document.((Please delete this text if not appropriate))

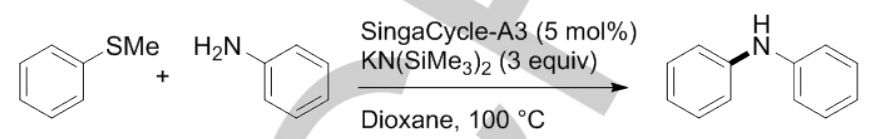

Scheme 1. Previous palladium-catalyzed amination of aryl sulfides with anilines.

\section{Results and Discussion}

To optimize conditions, we chose thioanisole (1a) and morpholine (2a) as model substrates. Since NHC ligands are uniquely effective for the previous amination via $\mathrm{C}-\mathrm{S}$ bond cleavage, modification of $\mathrm{NHC}$ ligands was our first strategy to achieve the amination. Thus, a variety of NHC ligands were synthesized to screen reaction conditions. However, any modified NHC ligands other than $\mathrm{IPr} \bullet \mathrm{HCl}$ (1,3-bis(2,6diisopropylphenyl)imidazolium chloride) were less effective

Table 1. Optimization of conditions ${ }^{[a]}$

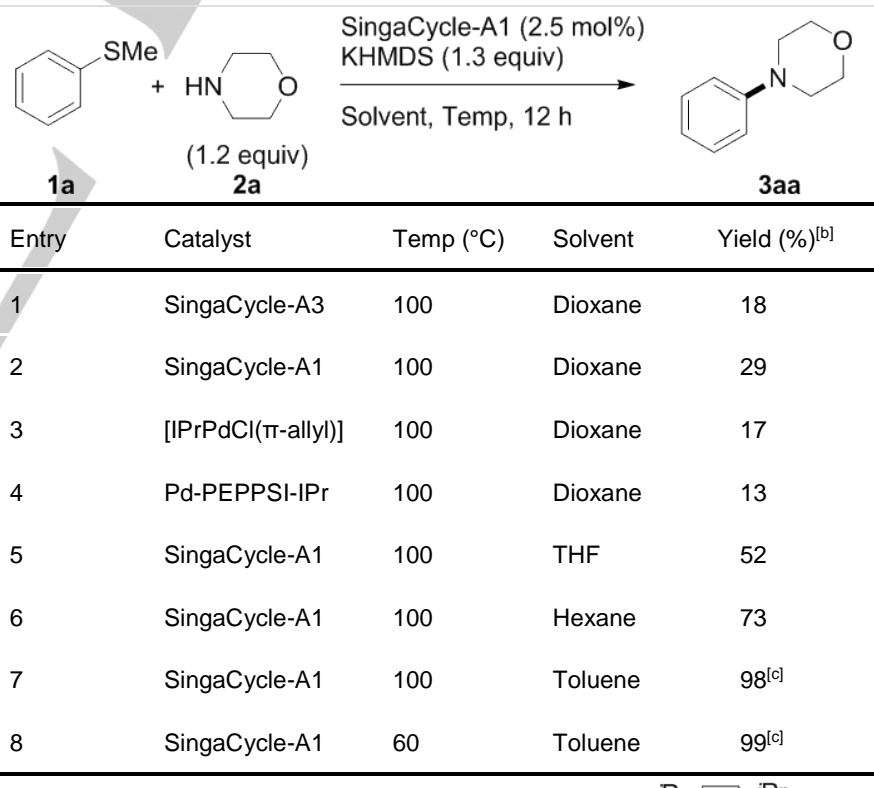

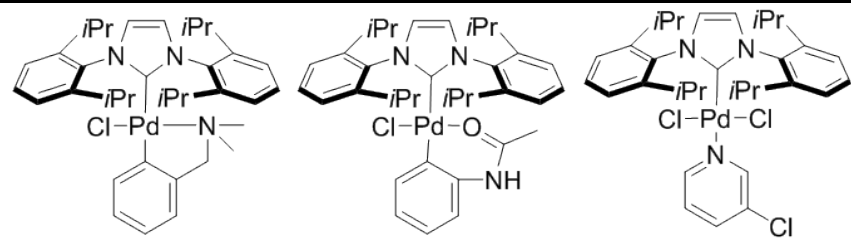

SingaCycle-A1

SingaCycle-A3

Pd-PEPPSI-IP

[a] The reaction was performed on a $0.5 \mathrm{mmol}$ scale. [b] Determined by NMR using 1,1,2,2-tetrachloroethane as an internal standard. [c] Isolated yield. 
(Table S1). ${ }^{[12]}$ Therefore, we then screened various $\mathrm{Pd}-\mathrm{IPr}$ precatalysts for the amination reaction. The results are summarized in Table 1 . SingaCycle-A ${ }^{[13]}$ in combination with $\mathrm{KN}\left(\mathrm{SiMe}_{3}\right)_{2}$ (KHMDS), which worked previously in the amination with anilines, ${ }^{[11 c]}$ afforded the corresponding amination product 3aa in only $18 \%$ yield (entry 1 ). In the presence of SingaCycle$A 1,{ }^{[14]}$ the yield of the desired product was increased to $29 \%$ (entry 2). Other palladium precatalysts such as $[\operatorname{IPrPdCl}(\pi-$ allyl) ${ }^{[15]}$ and Pd-PEPPSI-IPr ${ }^{[16]}$ were less effective (entries 3 and 4). The choice of the base, KHMDS, is critical for the reaction as other organic and inorganic bases including Grignard reagents, $\mathrm{KOtBu}$, and $\mathrm{K}_{2} \mathrm{CO}_{3}$ afforded trace amounts of 3aa or were totally ineffective. Importantly, nonpolar solvents worked much better than polar solvents (entries 5-7). The reaction afforded 3aa in $98 \%$ yield in toluene (entry 7 ). Furthermore, we are delighted to find that the reaction could take place even at $60{ }^{\circ} \mathrm{C}$ to afford 3aa in 99\% isolated yield (entry 8 ).

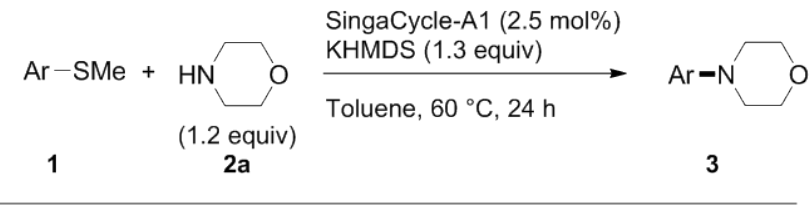<smiles>Cc1ccccc1N1CCOCC1</smiles>

3ba, $79 \%[a]$<smiles>Cc1cccc(N2CCOCC2)c1</smiles>

3ca, $91 \%[$ [a]

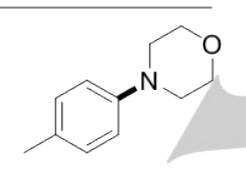

3da, $92 \%$<smiles>COc1ccc(N2CCOCC2)cc1</smiles>

3ea, $83 \%$<smiles>Fc1ccc(N2CCOCC2)cc1</smiles>

3 fa, $82 \%$<smiles>CC(C)(C)[13CH3]</smiles><smiles>CC1(C)COC(C)(c2ccc(N3CCOCC3)cc2)OC1</smiles>

TIPSO<smiles>FC(F)(F)c1ccc(N2CCOCC2)cc1</smiles>

3ga, $74 \%^{[b]}$

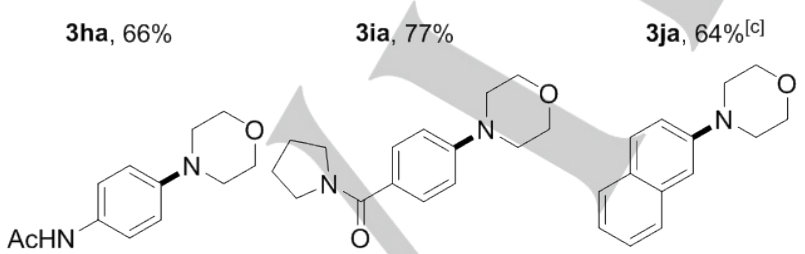

3ka, 35\%[a,d]

3ma, 59\% 3la, $64 \%[a, c]$
Scheme 2. Palladium-catalyzed amination of aryl sulfides with morpholine. The reaction was performed on a $0.5 \mathrm{mmol}$ scale. [a] The reaction was performed at $80{ }^{\circ} \mathrm{C}$. [b] $p-\mathrm{CF}_{3} \mathrm{C}_{6} \mathrm{H}_{4} \mathrm{SC}_{12} \mathrm{H}_{25}$ was used. [c] 5 mol\% SingaCycleA1, TIPS = triisopropylsilyl. [d] 10 mol\% SingaCycle-A1 and 2.3 equiv of KHMDS were used.
With the optimized conditions in hand, we examined the amination of various aryl sulfides with morpholine (Scheme 2). Sterically hindered ortho-methylphenyl sulfide $\mathbf{1 b}$ afforded the desired product $3 \mathrm{ba}$ in $79 \%$ yield at $80{ }^{\circ} \mathrm{C}$. Both electrondonating and electron-withdrawing groups at the para position of aryl sulfides did not have significant effect on reaction efficiency (3da-3la). para-Trifluoromethylphenyl sulfide was aminated with morpholine to yield 3ga while attempted amination with aniline failed in the previous report. ${ }^{[11 \mathrm{c}]}$ The reaction showed reasonable compatibility with functional groups including protected aldehyde (3ha) and ketone (3ia), TIPS-protected phenol (3ja), acetanilide (3ka), and amide (3la).

Subsequently, we explored the amination reaction of aryl sulfide with various amines (Scheme 3). Cyclic amines including piperidine, pyrrolidine, and 1-methylpiperazine reacted smoothly with thioanisole to afford the corresponding amination products 3ab-3ad in good yields. The reaction of piperazine afforded diarylation product $3 \mathbf{a e}$ in good yield with 2.2 equiv of thioanisole.

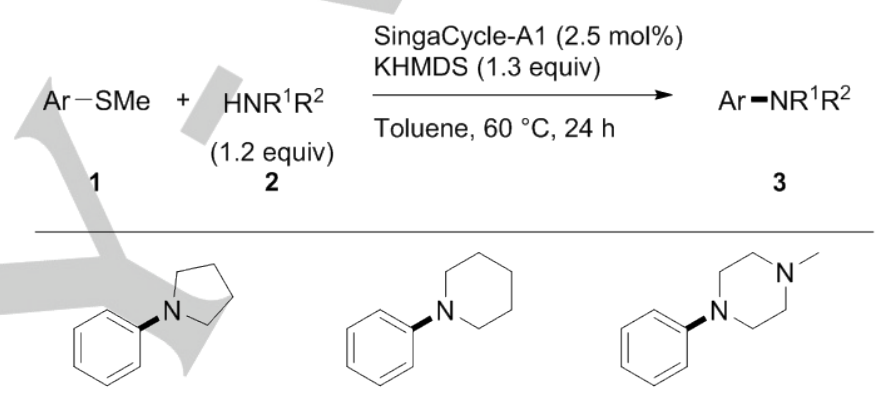

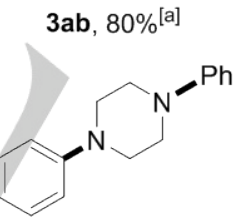

3ae, $74 \%[a, b, c]$<smiles>CC(C)(C)Nc1ccccc1</smiles>

3ah, $8 \%[a, c]$<smiles>Cc1cccc(C)c1Nc1ccccc1</smiles>

3ak, 70\% ${ }^{[a, c]}$ 3ac, $87 \%{ }^{[a]}$<smiles>CCC(C)Nc1ccccc1</smiles>

3af, $50 \%[a, c]$<smiles>Fc1ccccc1Nc1ccccc1</smiles>

3ai, $57 \%$<smiles>c1ccc(N2CCCc3ccccc32)cc1</smiles>

$3 a l, 62 \%[a, d]$ 3ad, $78 \%$<smiles>c1ccc(NC2CCCCC2)cc1</smiles>

3ag, $77 \%[\mathrm{a}, \mathrm{c}$<smiles>Cc1ccc(Nc2ccccc2)cc1</smiles>

3aj, $81 \%^{[a, c]}$

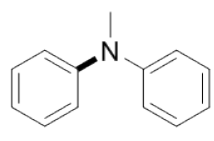

3am, 86\% ${ }^{[a, d]}$
Scheme 3. Palladium-catalyzed amination of aryl sulfides with various amines. The reaction was performed on a $0.5 \mathrm{mmol}$ scale. [a] The reaction was performed at $80{ }^{\circ} \mathrm{C}$. [b] 2.2 equiv of $1 \mathrm{a}$ was used. Piperazine is the limiting substrate. [c] 5 mol\% SingaCycle-A1. [d] 10 mol\% SingaCycle-A1. 
sec-Butylamine and cyclohexylamine also reacted in the presence of $5 \mathrm{~mol} \%$ SingaCycle-A 1 at $80{ }^{\circ} \mathrm{C}$ to afford secondary amines $\mathbf{3 a f}$ and $\mathbf{3 a g}$ without formation of diphenylated tertiary amines. Bulky tert-butylamine afforded product 3ah in miserable yield. The reaction of sterically less demanding octylamine afforded the desired product 3ai in $57 \%$ yield along with a diarylation product in $11 \%$ yield. The present conditions are also applicable to the amination with aromatic $p$-toluidine to afford 3aj in $81 \%$ yield at $80{ }^{\circ} \mathrm{C}$, proving comparable to the previous conditions. ${ }^{[11 \mathrm{c}]}$ Moreover, sterically hindered 2,6-dimethylaniline, 1,2,3,4-tetrahydroquinoline and $\mathrm{N}$-methylaniline were involved in the amination to yield the corresponding products $\mathbf{3 a k}, \mathbf{3 a l}$ and 3am, respectively, in good yields.

The amination of heteroaryl sulfides were also examined (Scheme 4). We are delighted to find that the reaction could proceed in the absence of SingaCycle-A1. The catalyst-free amination of 2-pyridyl sulfide afforded product 3na in $43 \%$ yield, while the yield could increase to $90 \%$ in the presence of SingaCycle-A1. Other heteroaryl sulfides such as 2-pyrazyl sulfide, 2-(1-methylbenzimidazolyl), and 2-benzothiazolyl sulfide were aminated with morpholine smoothly to afford the corresponding products $3 \mathbf{0 a}, 3 \mathbf{p a}$, and $\mathbf{3 q a}$, respectively. Both primary and secondary amines reacted with 2-benzothiazolyl sulfide to afford the amination products $\mathbf{3 q b} \mathbf{3 q m}$ in good to excellent yields. Similar displacement of heteroaryl sulfones and sulfoxides with amines is known. ${ }^{[17,18]}$ However, there are rare reports of direct displacement of heteroaryl sulfides with amines with limited examples. ${ }^{[19]}$ The KHMDS-mediated amination of heteroaryl sulfides provides a more general protocol for the functionalization of heteroaryl sulfides.
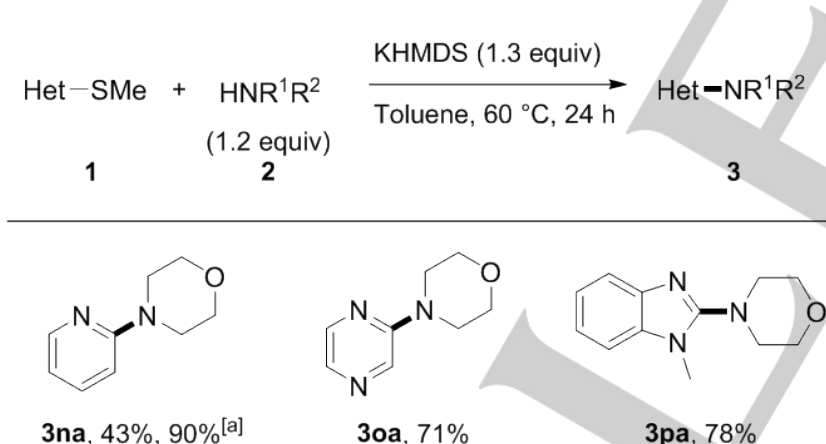

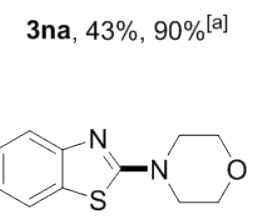

3qa, $90 \%$
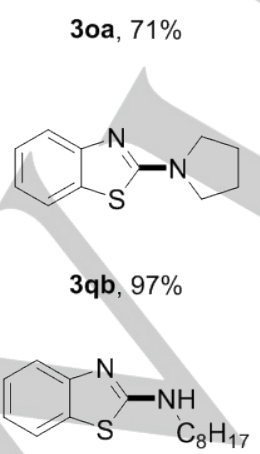

$3 q i, 86 \%{ }^{[b]}$

$3 q m, 82 \%$

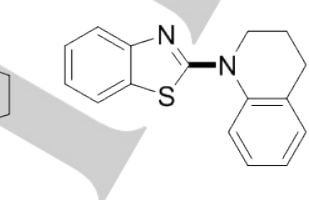

$3 q \mathrm{l}, 95 \%$<smiles>Brc1ccccc1Nc1nc2ccccc2s1</smiles>

$3 q$ n, $71 \%[\mathrm{~b}]$
Scheme 4. Catalyst-free amination of heteroaryl sulfides with various amines. The reaction was performed on a $0.5 \mathrm{mmol}$ scale. [a] In the presence of
SingaCycle-A1 (2.5 mol\%). [b] 2.2 equiv of amine and 2.3 equiv of KHMDS were used.

We found that the amination reactions of $p$-bromothioanisole proceeded preferentially at the $\mathrm{C}-\mathrm{Br}$ bond while the $\mathrm{C}-\mathrm{S}$ bond remained untouched (Scheme 5). The exclusive conversions of the $\mathrm{C}-\mathrm{Br}$ bond allowed us to install two different amino groups onto the aromatic ring in one pot. The second amination was highly selective to afford diaminobenzenes 3rba, 3rca, and 3rad in high yields.

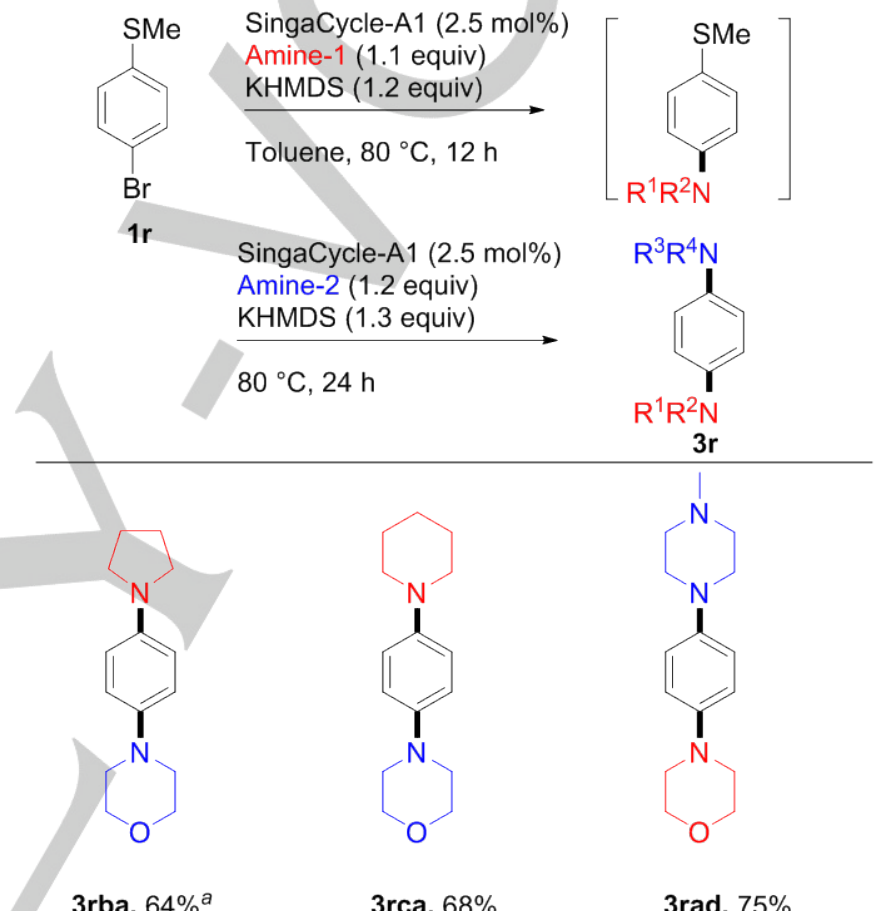

Scheme 5. The amination of heteroaryl sulfides with various amines. The reaction was performed on a $0.5 \mathrm{mmol}$ scale. [a] $5 \mathrm{~mol} \%$ SingaCycle-A1 was used in the second amination.

\section{Conclusions}

We have developed palladium-catalyzed amination of aryl sulfides with aliphatic amines. The reaction proceeded under milder conditions compared to the previous amination with aromatic amines. The amination of heteroaryl sulfides could proceed in the absence of a palladium catalyst. The different reactivities of a $\mathrm{C}-\mathrm{S}$ bond and a $\mathrm{C}-\mathrm{Br}$ bond allowed us to install different amino groups onto an aromatic ring in one pot, which could be a useful protocol for organic synthesis.

\section{Experimental Section}

General procedure for palladium-catalyzed amination of aryl sulfides with aliphatic amines 
In a Schlenk tube were placed SingaCycle-A1 $(8.3 \mathrm{mg}, 0.0125 \mathrm{mmol})$, thioanisole (1a, $62.1 \mathrm{mg}, 0.50 \mathrm{mmol})$, and morpholine (2a, $52.3 \mathrm{mg}, 0.60$ $\mathrm{mmol})$. To the mixture was added a toluene solution of $\mathrm{KN}\left(\mathrm{SiMe}_{3}\right)_{2}(0.5$ $\mathrm{M}, 1.3 \mathrm{~mL}, 0.65 \mathrm{mmol})$. The resulting mixture was stirred at $60^{\circ} \mathrm{C}$ for 12 h. The reaction was quenched by addition of saturated $\mathrm{NH}_{4} \mathrm{Cl}$ solution $(1.0 \mathrm{~mL})$ and then extracted with ethyl acetate $(3 \times 10 \mathrm{~mL})$. The combined organic layer was dried over $\mathrm{Na}_{2} \mathrm{SO}_{4}$ and concentrated under reduced pressure. The crude product was purified by silica gel chromatography (eluent: hexane/EtOAc $=10 / 1-5 / 1$ ) to afford the desired product 3aa as an orange solid $(82.2 \mathrm{mg}, 0.50 \mathrm{mmol}, 99 \%)$

\section{Acknowledgements}

This work was supported by Grants-in-Aid for Scientific Research from MEXT (No.: 25107002 "Science of Atomic Layers") and from JSPS (Nos.: 24685007 (Young Scientists (A)) and 26620081 (Exploratory Research)). K.G. acknowledges JSPS Postdoctoral Fellowship for Foreign Researchers.

Keywords: Amination $•$ Aryl sulfides $\bullet \mathrm{C}-\mathrm{S}$ bond cleavage $\bullet \mathrm{N}$ heterocyclic carbene ligands $\bullet$ Palladium

[1] a) L.-L. Li, E. W. Diau, Chem. Soc. Rev. 2013, 42, 291-304; b) K. Walzer, B. Maennig, M. Pfeiffer, K. Leo, Chem. Rev. 2007, 107, 1233 1271; c) J. A. Bikker, N. Brooijmans, A. Wissner, T. S. Mansour. J. Med Chem. 2009, 52, 1493-1509; d) M.-Y. Chou, M.-K. Leung, Y. O. Su, C L. Chiang, C.-C. Lin, J.-H. Liu, C.-K. Kou, C.-Y. Mou, Chem. Mater. 2004, 16, 654-661; e) P. Strohriegl, J. V. Grazulevicius, Adv. Mater. 2002, 14, 1439-1452.

[2] Recent reviews: a) T. R. M. Rauws, B. U. W. Maes, Chem. Soc. Rev. 2012, 41, 2463-2497; b) C. Valente, S. Calimsiz, K. H. Hoi, D. Mallik, M Sayah, M. G. Organ, Angew. Chem. 2012, 124, 3370-3388; Angew. Chem. Int. Ed. 2012, 51, 3314-3332; c) J. Magano, J. R. Dunetz, Chem Rev. 2011, 111, 2177-2250; d) G. C. Fortman, S. P. Nolan, Chem. Soc. Rev. 2011, 40, 5151-5169; e) J. F. Hartwig, Acc. Chem. Res. 2008, 41 1534-1544; f) D. S. Surry, S. L. Buchwald, Angew. Chem. 2008, 120 6348-6461; Angew. Chem. Int. Ed. 2008, 47, 6338-6361.

[3] Selected very recent examples: a) M. Pompeo, J. L. Farmer, R. D. J. Froese, M. G. Organ, Angew. Chem. 2014, 126, 3287-3290; Angew. Chem. Int. Ed. 2014, 53, 3223-3226; b) Y. Zhang, V. César, G. Storch N. Lugan, G. Lavigne, Angew. Chem. 2014, 126, 6600-6604; Angew. Chem. Int. Ed. 2014, 53, 6482-6486; c) S. Riedmüller, O. Kaufhold, H. Spreitzer, B. J. Nachtsheim, Eur. J. Org. Chem. 2014, 1391-1394; d) M. Su, N. Hoshiya, S. L. Buchwald, Org. Lett. 2014, 16, 832-835.

[4] a) J. Cornella, C. Zarate, R. Martin, Chem. Soc. Rev. 2014, 43, 80818097; b) T. Mesganaw, N. K. Garg, Org. Process Res. Dev. 2013, 17 29-39.

[5] a) T. Mesganaw, A. L. Silberstein, S. D. Ramgren, N. F. F. Nathel, X. Hong, P. Liu, N. K. Garg, Chem. Sci. 2011, 2, 1766-1771; b) L. Hie, S. D. Ramgren, T. Mesganaw, N. K. Garg, Org. Lett. 2012, 14, 4182-4185.

[6] a) S. D. Ramgren, A. L. Silberstein, Y. Yang, N. K. Garg, Angew. Chem. 2011, 123, 2219-2221; Angew. Chem. Int. Ed. 2011, 50, 2171-2173; b) L. Ackermann, R. Sandmann, W. Song, Org. Lett. 2011, 13, 1784-1786; c) H. Tadaoka, T. Yamakawa, Tetrahedron Lett. 2013, 53, 5531-5534; d) N. F. F. Nathel, J. Kim, L. Hie, X. Jiang, N. K. Garg, ACS Catal. 2014
4, 3289-3293; e) N. H. Park, G. Teverovskiy, S. L. Buchwald, Org. Lett. 2014, 16, 220-223

[7] T. Shimasaki, M. Tobisu, N. Chatani, Angew. Chem. 2010, 122, 2991 2994; Angew. Chem. Int. Ed. 2010, 49, 2929-2932.

[8] J.-H. Huang, L.-M. Yang, Org. Lett. 2011, 13, 3750-3753.

[9] a) M. Tobisu, T. Shimasaki, N. Chatani, Chem. Lett. 2009, 38, 710-711; b) M. Tobisu, A. Yasutome, K. Yamakawa, T. Shimasaki, N. Chatani, Tetrahedron 2012, 68, 5157-5161.

[10] Reviews: a) H. Sugimura, H. Okamura, M. Miura, M. Yoshida, F. Takei Nippon Kagaku Kaishi 1985, 416-424; b) F. Naso, Pure Appl. Chem. 1988, 60, 79-88; c) T.-Y. Luh, Z.-J. Ni, Synthesis 1990, 89-103; d) T.-Y. Luh, Acc. Chem. Res. 1991, 24, 257-263; e) V. Fiandanese, Pure Appl. Chem. 1990, 62, 1987-1992; f) S. R. Dubbaka, P. Vogel, Angew. Chem. 2005, 117, 7848-7859; Angew. Chem. Int. Ed. 2005, 44, 7674-7684; g) H. Prokopcová, C. O. Kappe, Angew. Chem. 2008, 120, 3732-3734 Angew. Chem. Int. Ed. 2008, 47, 3674-3676; h) L. Wang, W. He, Z. Yu, Chem. Soc. Rev. 2013, 42, 599-621; i) S. G. Modha, V. P. Mehta, E. V. Van der Eycken, Chem. Soc. Rev. 2013, 42, 5042-5055; j) F. Pan, Z.-J. Shi, ACS Catal. 2014, 4, 280-288.

[11] a) Y. Ookubu, A. Wakamiya, H. Yorimitsu, A. Osuka, Chem. Eur. J. 2012, 18, 12690-12697; b) K. Murakami, H. Yorimitsu, A. Osuka, Angew. Chem. 2014, 126, 7640-7643; Angew. Chem. Int. Ed. 2014, 53, 7510-7513; c) T. Sugahara, K. Murakami, H. Yorimitsu, A. Osuka Angew. Chem. 2014, 126, 9483-9487; Angew. Chem. Int. Ed. 2014, 53 9329-9333; d) S. Otsuka, D. Fujino, K. Murakami, H. Yorimitsu, A Osuka, Chem. Eur. J. 2014, 20, 13146-13149; e) A. Baralle, S. Otsuka V. Guérin, K. Murakami, H. Yorimitsu, A. Osuka, Synlett 2015, DOI: 10.1055/s-0034-1378914.

[12] See Supporting Information.

[13] G.-R. Peh, E. A. B. Kantchev, J.-C. Er, J. Y. Ying, Chem. Eur. J. 2010 16, 4010-4017.

[14] a) G.-R. Peh, E. A. B. Kantchev, C. Zhang, J. Y. Ying, Org. Biomol Chem. 2009, 7, 2110-2119; b) E. A. B. Kantchev, J. Y. Ying Organometallics 2009, 28, 289-299.

[15] a) O. Navarro, H. Kaur, P. Mahjoor, S. P. Nolan, J. Org. Chem. 2004 69 , 3173-3180; b) M. S. Viciu, R. F. Germaneau, O. NavarroFernandez, E. D. Stevens, S. P. Nolan, Organometallics 2002, 21, 5470-5472.

[16] a) C. Valente, S. Çalimsiz, K. H. Hoi, D. Mallik, M. Sayah, M. G. Organ Angew. Chem. 2012, 124, 3370-3388; Angew. Chem. Int. Ed. 2012, 51 3314-3332; b) C. Valente, M. Pompeo, M. Sayah, M. G. Organ, Org Process Res. Dev. 2014, 18, 180-190; c) E. A. B. Kantchev, C. J. O'Brien, M. G. Organ, Aldrichmica Acta 2006, 39, 117-130.

[17] Selected examples of amination of sulfones: a) Q. Ren, W. Mo, L. Gao, H. He, Y. G. J. Heterocyclic Chem. 2010, 47, 171-178; b) Y. Nomoto, H. Takai, T. Ohno, K. Kubo, Chem. Pharm. Bull. 1991, 39, 352-357; c) L. Gong, S. Mateo, R. S. Wilhelm, L. Altos, Patent Appl. US2005/0090504A1, 2005

[18] Selected examples of amination of sulfoxides: a) H. Morita, S. Tashiro M. Takeda, N. Yamada, Md. C. Sheikh, H. Kawaguchi, Tetrahedron 2008, 64, 4496-4505; b) S. J. Teague, J. Org. Chem. 2008, 73, 97659766; c) M. J. Hadd, H. D. Hocker, Patent Appl. WO2013/056070A2, 2013; d) J. C. Sutton, M. Wiesmann, Patent Appl. WO2007/121484A2, 2007; e) H. Knust, M, Nettekoven, E. Pinard, O. Roche, M. RogersEvans, Patent Appl. US2009/0163485A1, 2009; f) S. Harbeson, R. D. Tung, Patent Appl. WO2010/127272A2, 2010

[19] a) D. A. Ibrahim, N. S. M. Ismail, Eur. J. Med. Chem. 2011, 46, 58255832; b) E. Auustyn, K. Bogdanowicz-Szwed, Monatsh. Chem. 1983 $114,1189-1196$ 
Entry for the Table of Contents (Please choose one layout)

Layout 2:

\section{FULL PAPER}

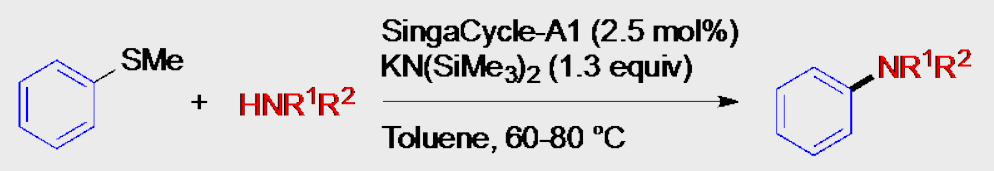

K. Gao, H. Yorimitsu, *A. Osuka

Page No. - Page No.

Palladium-Catalyzed Amination of

Aryl Sulfides with Aliphatic Amines

A palladium-NHC precatalyst exhibits high efficiency on $\mathrm{C}-\mathrm{S}$ bond cleavage for amination of aryl sulfides with aliphatic amines as well as aromatic amines. 